\title{
Aviation Meteorology: Observations and Models. Introduction
}

\author{
Ismail Gultepe ${ }^{1,2}$ and Wayne F. Feltz ${ }^{3}$
}

This special issue of Pure and Applied Geophysics contains an introduction plus 14 papers related to Aviation Meteorology. The papers cover important topics such as wind, gust, turbulence, visibility related to fog and precipitation, convection and lightning, icing, and high ice water content and engine icing. These research areas are important to develop applications for aviation meteorology, and in particular, aviation operations. The results discussed in this special issue are generated by research efforts conducted internationally, and include several review papers. Review papers on aviation meteorology (Gultepe et al. 2019a), gravity waves and convectively-induced turbulence (Sharman and Trier 2019), lidars (Thobois et al. 2019), and geostationary satellites (Ellrod and Pryor 2019), as well as supersite observations (Gultepe et al. 2019b) provided extensive details for operational applications. Some of these papers were included in various international conferences, including the EGU (European Geophysical Union) aviation meteorology sessions, that took place in Vienna, Austria, during 2016-2018.

Aviation meteorology covers many interrelated subjects and engineering topics. These include ground-based operations that are related to adverse effect of frost, ice, snow, and visibility on aircraft performance and in-flight icing and turbulence. The effects of these on aircraft are decreased thrust and

1 Meteorological Research Division (MRD), Environment and Climate Change Canada (ECCC), Toronto, ON M3H 5T4, Canada. E-mail: ismail.gultepe@canada.ca; Ismail.gultepe@ uoit.ca

2 The Faculty of Engineering and Applied Science, Ontario Technical University (OTU), Oshawa, ON L1G 0C5, Canada.

3 Space Science and Engineering Center/Cooperative Institute for Meteorological Satellite Studies (SSEC/CIMSS) UW, Madison, WI, USA. E-mail: wayne.feltz@ssec.wisc.edu lift, increased drag, increased stall speed, and modified handling characteristics (TC AIM 2019; Bragg et al. 2000). TC AIM report suggested that the type of frost, ice or snow, that can accumulate on an aircraft, while on the ground, is a key factor in determining the type of de-icing/anti-icing procedures. Figure 1 shows an icing event that occurred during an aircraft icing project, which took place in Eastern Canada (a) (Isaac et al. 2005), and a severe frost condition that occurred during an ice fog project (b) (Gultepe et al. 2015). At the ground stops for aircraft, wet snow, freezing drizzle, or rain, with the ambient temperature around $0{ }^{\circ} \mathrm{C}$ or even in a temperature range between $8^{\circ}$ and $14{ }^{\circ} \mathrm{C}$, can be critical for aviation operations (TC AIM 2019).

Wind shear and turbulence conditions can also be critical for aircraft flight conditions, as clear air turbulence (CAT) can be reported anywhere during a flight path. The CAT events are usually related to frontal weather systems and jet cores called jet streaks (Fig. 2), with a sketch adapted from TC AIM (2019), showing the possible areas of CAT conditions at the higher level of atmosphere (Fig. 2a). Figure 2b shows the airflow streamlines behind an aircraft taking off, indicating vortex core and vortex flow directions. Based on these issues, the current special issue will present the recent works to advance the aviation meteorology science and operations.

For this volume we focused on scientific and operational issues that affect flight conditions, such as aircraft climb, and drag and lift forces. The review paper by Gultepe et al. (2019a) clearly shows that wind, turbulence (including gust), and visibility are more often a cause of aircraft flight disruptions, rather than other factors, such as icing conditions studied in Chuang et al. (2019), convection, and pollution-dust, which also play important roles for aviation operations. Therefore, more research is needed to 

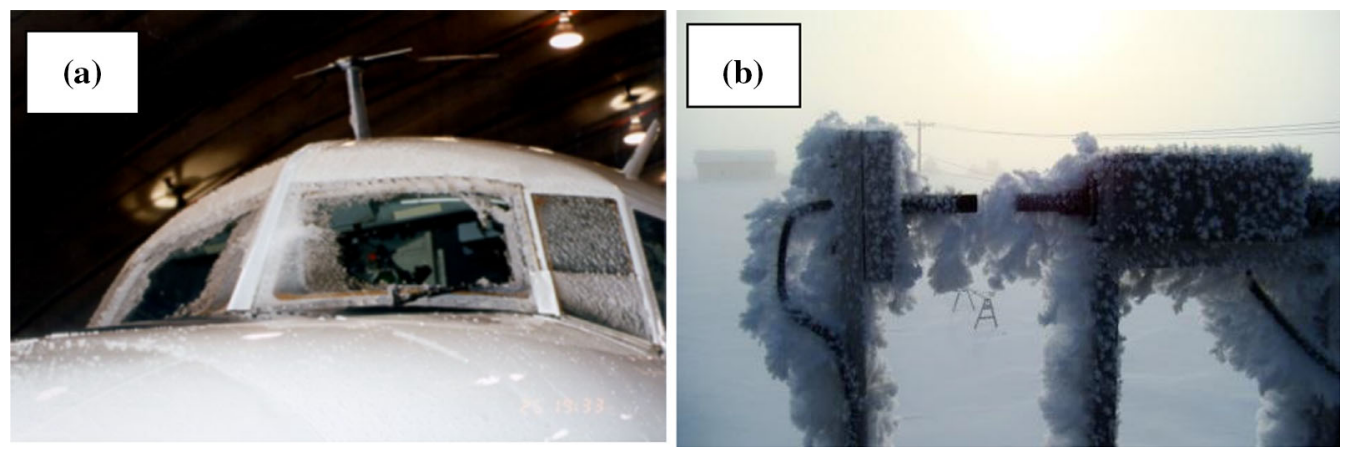

Figure 1

Shows icing occurred on NRC Convair during AIRS II field project (Isaac et al. 2005) (a) and frost happened during FRAM ice fog project (Gultepe et al. 2015, which took place in Barrow, Alaska, USA in April of 2008 (b). Pictures were taken by I. Gultepe
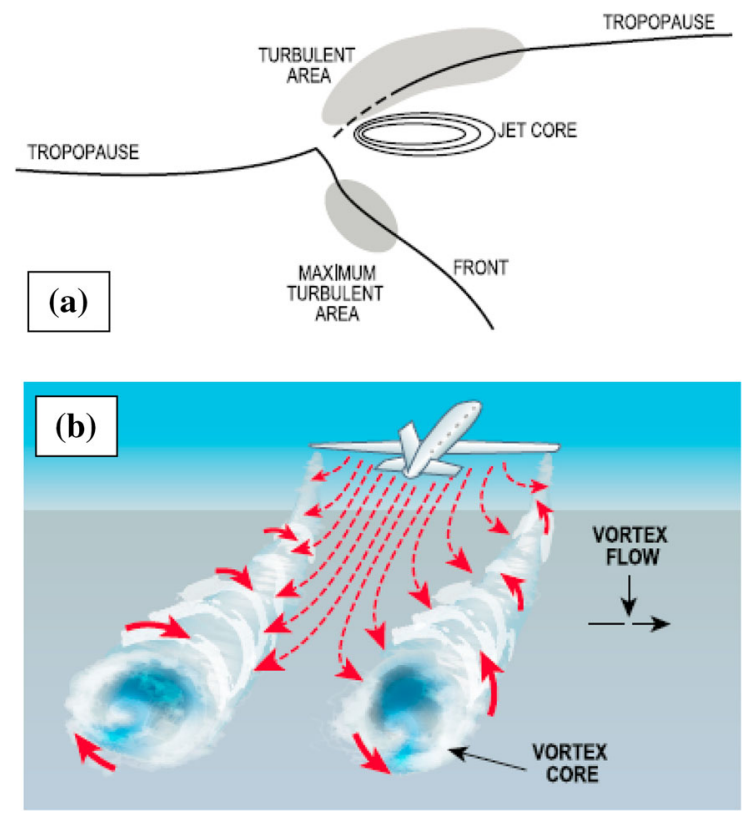

Figure 2

Possible areas of turbulence and CAT related to a jet streak, front, and tropopause (a), and a wake vortex conceptual design (b) (Adapted from TC AIM 2019)

characterize aircraft flying conditions and ground based operations and environments.

Aviation meteorology needs new instrumental platforms and analysis techniques to improve safety conditions for flight environments. These platforms need to be developed as a part of integrated systems, such as ground based in situ observations, and remote sensing platforms, that include both ground and space based operational satellites. Although presently unmanned aerial vehicle (UAV) and unmanned aerial systems (UAS) platforms have not been used for operations, they are becoming very popular for atmospheric research, especially for dangerous conditions such as hurricanes, convective storms, and icing environments (Griffin and Velden 2019), as well as NWP (numerical weather prediction) simulations and initializations. The UAVs can carry various miniature sensors for weather research and observations (Gultepe et al. 2019b). In this topical special issue, the importance of UAVs for future atmospheric research has also been emphasized for high level and low-level flight conditions and weather research.

Ground based in situ observations of various aviation meteorology related parameters can be obtained for extreme weather conditions within climate and wind tunnel laboratories (Gultepe et al. 2019b). Two of these, including the University of Ontario Institute of Technology (UOIT) climatic wind tunnel (CWT) and NASA Glen wind tunnel, have been used for simulating Arctic and icing environments, respectively (Gultepe et al. 2019a). Climatic wind tunnel tests are also important for simulating aircraft aerodynamic conditions that had been summarized by many others (Dodson 2005; Tomek et al. 2006; Bell 2002; Ross 2011).

Weather forecasts have been improved over short and long-time periods, using various analysis systems, such as NWP models (Chachere and Pu 2019), nowcasting-based systems, integrated methods, and statistical-based methods such as neural network and 
artificial intelligence (AI) systems (Kneringer et al. 2019; Zheng et al. 2018). This topical issue provides the current status and challenges of these systems. While none of these systems alone can provide accurate predictions of meteorological parameters over short or long-time periods, integrating these methods can be used more confidently to improve aircraft physical and managerial flying conditions, including conditions on the ground (Kutty et al. 2019; França et al. 2019). Several papers focusing on these issues are included in this issue.

The accuracy of forecasting and nowcasting aviation weather using numerical models and remote sensing techniques still remains difficult, mainly because of the lack of observations for physical and dynamical parameterizations as a part of numerical models (Weston et al. 2019). Presently, typical numerical forecast models lack sufficient time and space resolutions and appropriate physical parameterizations to represent aircraft scales $(10-100 \mathrm{~m})$ in estimating aerodynamic and microphysical processes. Simple approaches, e.g., using only temperature and relative humidity with respect to water $\left(\mathrm{RH}_{\mathrm{w}}\right)$ to calculate icing rates, can lead to uncertainties of more than $30 \%$ in many conditions.

This topical special issue points out that improvements of in situ observations and microphysical parameterizations are required to reduce aviation related accidents. Pu et al. (2019) stated the importance of microphysical parameterizations for convective systems and NWP sensitivity for various parameterizations. However, detailed 3D models do not represent certain scales and use large scale parameterizations for predictions; furthermore, these 3D models are currently not practical to be used operationally because of processing time of numerical algorithms based on smaller time and space scales. The capability of these models needs to be improved mainly for wind speed and direction, gust, visibility and ceiling, convection, and icing conditions. For example, Gultepe et al. (2019a) stated that on average, 60 people die because of fog-related accidents every year in Canada, which is comparable to impacts resulting from other severe weather events, and these numbers can be much higher based on international considerations. In fact, the worst accident in aviation history occurred due to fog and low visibility impacting aircraft take off processes on
March 27, 1977. Two Boeing 747 passenger airliners collided on the runway of Tenerife Airport on the Spanish island of Tenerife, one of the Canary Islands. The crash claimed a total of 583 fatalities (Smith 2017). As is the case in most weather-related aviation accidents, several conditions combined leading to the accident occurrence, however certainly dense fog played a critical role. The two aircraft would have been aware of one another's presence in fair conditions, but because of dense fog, neither aircraft could see one another until it was too late.

Global climate change issues are also critical for aviation operations. For example, temperature changes of a few ${ }^{\circ} \mathrm{C}$ can impact aircraft aerodynamical conditions such as lift and drag, as well as climb rates (Storer et al. 2019). Regional air pollution issues, including volcanic ash and dust conditions, also affect flying conditions; but aircraft contrail formation due to exhaust gases during taking off or landing can also affect the weather and climate (Gultepe et al. 2014; Heymsfield et al. 1998, 2010; Schumann 2002, 2005). Schumann and Heymsfield (2017) stated that key parameters controlling contrail properties, besides aircraft and fuel properties, ambient pressure, temperature, and humidity, can be related to the number of ice particles per flight distance surviving the wake vortex phase, the contrail depth and particle sedimentation, wind shear, turbulence, and vertical motions controlling contrail dispersion. Contrail effect on climate change depends also on the ratio of shortwave to longwave radiative forcing (RF) that contributes to surface warming. Figure 3 shows a contrail formation during an aircraft take off at the Yellow Knife International Airport, NWT, Canada (Fig. 3a, b). Figure 3c shows a contrail occurred due to a condensation process related to an aircraft jet exhaust (Schumann and Heymsfield 2017). However, we are just starting to understand these conditions and develop new methods to better evaluate contrail impact on the climate change, and develop, mitigation steps to reduce risk-related aircraft accidents and aircraft-related pollution.

Wind and turbulence activities factor into the aircraft landings and takeoffs conditions (Sharman and Trier 2019). In reality, wind measurements at airports lack the needed resolution over the horizontal and vertical scales. Therefore, improvements in wind measurements can only be done by using state of the art 

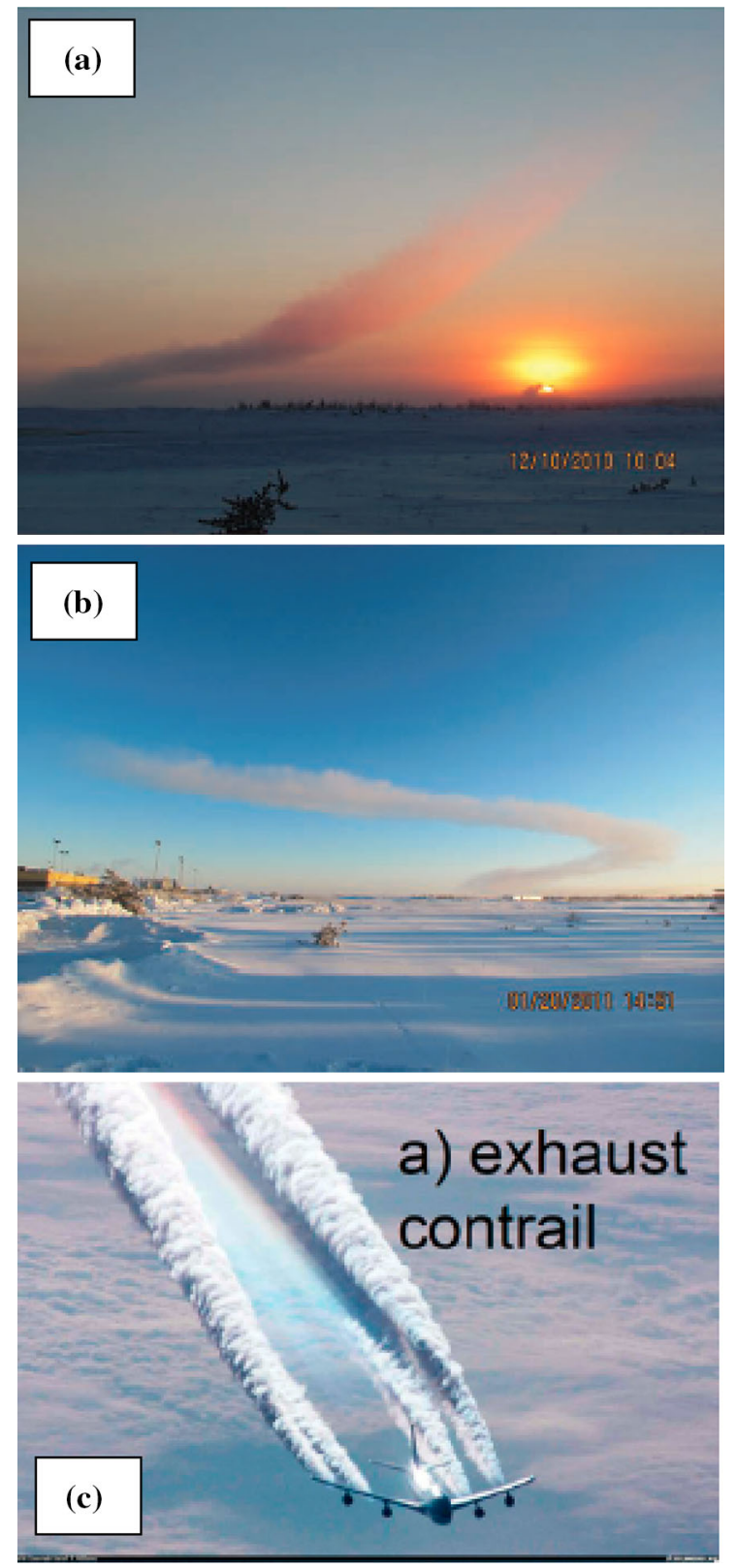

Figure 3

a is for a contrail formation after an aircraft takes off at 1004 local standard time (LST) 10 December 2010; b another contrail on 1451 LST 20 January 2011 over Yellowknife International Airport (adapted from Gultepe et al. 2014), and c exhaust contrail at the upper atmosphere (adapted from Schumann and Heymsfield 2017).

Permission by American Meteorological Society

observational platforms such as lidars and UAVs (Thobois et al. 2019; Gultepe et al. 2019b). Doppler lidars (Thobois et al. 2019) adaptable for airport use can provide wind speed, directional shear, gust, and turbulence conditions over short time and space scales at airports and during landings and takeoffs. As a result, these new platforms can be used to more accurately define safety conditions for aviation applications.

While this publication broadly covers the whole of aviation meteorology, less information on Polar flight conditions is noted, although major issues related to cold temperature and snow conditions, as well as ice fog, are discussed extensively. To simulate Polar conditions, climate wind tunnels (e.g., UOIT CWT, Gultepe et al. 2019b) can be used to test aircraft parts and pieces, but these also need to be validated using real flight environments. In reality, freezing fog and ice fog occur often in cold climates, particularly in the high Arctic and Antarctic regions, and can create adverse weather conditions for aviation and marine applications, that need to be addressed seriously as air traffic and marine transportation increases over the Arctic regions.

\section{Acknowledgements}

Guest editors wish to thank the scientific contributors to this topical issue and we also gratefully acknowledge funding support for Editor I. Gultepe by Environment and Climate Change Canada (ECCC) and the Canadian National Search and Rescue (SAR) Secretariat. In addition, our sincere thanks go to Drs. Renata Dmowska and Alexander Rabinovich, Editors in Chief for topical and regular issues at Pure and Applied Geophysics, for inviting our working group to prepare this topical issue, handling the review process and providing invaluable advice. Special thanks are also given to all contributors, who submitted their valuable work to this topical issue as well as to all reviewers.

Publisher's Note Springer Nature remains neutral with regard to jurisdictional claims in published maps and institutional affiliations.

\section{REFERENCES}

Bell, J. (2002). Comparison of crew exploration vehicle (CEV) tests in two supersonic wind tunnels. In AIAA 2007-1008, 45th AIAA aerospace sciences meeting and exhibit, Reno, NV, January 2007. 
Bragg, M., Hutchison, T., Merret, J., Oltman, R., \& Pokhariyal, D. (2000). Effect of ice accretion on aircraft flight dynamics. In 38th AIAA aerospace sciences meeting \& exhibit. Urbana, Illinois 61801.

Chachere, C. N., \& Pu, Z. (2019). Numerical simulations of an inversion fog event in the salt lake valley during the MATERHORN-Fog field campaign. Pure and Applied Geophysics. https://doi.org/10.1007/s00024-018-1770-8.

Chuang, H. Y., Mao, Y., \& Zhou, B. (2019). R2O transition of NCAR's icing and turbulence algorithms into NCEP's operations. Pure and Applied Geophysics. https://doi.org/10.1007/s00024-018-1975-x.

Dodson, M. G. (2005). An historical and applied aerodynamic study of the Wright Brothers' wind tunnel test program and application to successful manned flight. In US Naval Academy Technical Report. USNA-334. Accessed 03 Nov 2009.

Ellrod, G. P., \& Pryor, K. (2019). Applications of geostationary satellite data to aviation. Pure and Applied Geophysics. https:// doi.org/10.1007/s00024-018-1821-1.

França, G. B., do Carmo, L. F. R., de Almeida, M. V., \& Neto, F. L. A. (2019). Fog at the Guarulhos International Airport from 1951 to 2015. Pure and Applied Geophysics. https://doi.org/10. 1007/s00024-018-1781-5.

Griffin, S. M., \& Velden, C. S. (2019). Hazard avoidance products for convectively-induced turbulence in support of high-altitude global hawk aircraft missions. Pure and Applied Geophysics. https://doi.org/10.1007/s00024-018-1772-6.

Gultepe, I., Agelin-Chaab, M., Komar, J., Elfstrom, G., Boudala, F., \& Zhou, B. (2019b). A meteorological supersite for aviation and cold weather applications. Pure and Applied Geophysics. https://doi.org/10.1007/s00024-018-1880-3.

Gultepe, I., Kuhn, T., Pavolonis, M., Calvert, C., Gurka, J., Isaac, G. A., et al. (2014). Ice fog in Arctic during FRAM-IF project: Aviation and nowcasting applications. Bulletin of American Meteorological Society, 95, 211-226.

Gultepe, I., Sharman, R., Williams, P. D., Zhou, B., Ellrod, G., Minnis, P., Trier, S., Griffin, S., Yum, S. S., Gharabaghi, B., Feltz, W., Temini, M., Pu, Z., Storer, L. N., Kneringer, P., Weston, M. J., Chuang, H. Y., Thobois, L., Dimri, A. P., Dietz, S. J., Gutenberg, M., Almeida, M. V., \& Neto, F. L. A. (2019a). A review of high impact weather for aviation meteorology. Pure and Applied Geophysics. https://doi.org/10.1007/s00024-019-02168-6.

Gultepe, I., Zhou, B., Milbrandt, J., Bott, A., Li, Y., Heymsfield, A. J., et al. (2015). A review on ice fog measurements and modeling. Atmospheric Research, 151, 2-19.

Heymsfield, A. J., Baumgardner, D., DeMott, P., Forster, P., Gierens, K., \& Kärcher, B. (2010). Contrail microphysics. Bulletin of American Meteorological Society, 91, 465-472. https://doi.org/ 10.1175/2009BAMS2839.1.

Heymsfield, A. J., Lawson, R. P., \& Sachse, G. W. (1998). Growth of ice crystals in a precipitating contrail. Geophysical Research Letters, 25, 1335-1338. https://doi.org/10.1029/98GL00189.

Isaac, G. A., Ayers, J. K., Bailey, M., Bissonnette, L., Bernstein, B. C., Cober, S. G., Driedger, N., Evans, W. F. J., Fabry, F., Glazer, A., Gultepe, I., Hallett, J., Hudak, D., Korolev, A. V., Marcotte, D., Minnis, P., Murray, J., Nguyen, L., Ratvasky, T. P., Reehorst, A., Reid, J., Rodriguez, P., Schneider, T., Sheppard, B. E., Strapp, J. W., $\&$ Wolde, M. (2005). First results from the alliance icing research study (AIRS-II). In 43rd AIAA aerospace sciences meeting and exhibit 10-13 January 2005, Reno, Nevada, AIAA 2005-252.

Kneringer, P., Dietz, S. J., Mayr, G. J., \& Zeileis, A. (2019). Probabilistic nowcasting of low-visibility procedure states at Vienna International Airport during cold season. Pure and Applied Geophysics. https://doi.org/10.1007/s00024-018-1863-4.

Kutty, S. G., Agnihotri, G., Dimri, A. P., \& Gultepe, I. (2019). Fog occurrence and associated meteorological factors over Kempegowda International Airport, India. Pure and Applied Geophysics. https://doi.org/10.1007/s00024-018-1882-1.

Pu, Z., Lin, C., Dong, X., \& Krueger, S. K. (2019). Sensitivity of numerical simulations of a mesoscale convective system to ice hydrometeors in bulk microphysical parameterization. Pure and Applied Geophysics. https://doi.org/10.1007/s00024-018-1787-z.

Ross, J. C. (2011). Aerodynamic and aeroacoustic wind tunnel testing of the Orion spacecraft. In AIAA 2011-0014395. Applied Aerodynamics; 15 June 2011; Honolulu, HI; United States.

Schumann, U. (2002). Contrail cirrus. In D. K. Lynch, et al. (Eds.), Cirrus (pp. 231-255). Oxford: Oxford University Press.

Schumann, U. (2005). Formation, properties and climate effects of contrails. Comptes Rendus Physique, 6, 549-565. https://doi.org/ 10.1016/j.crhy.2005.05.002.

Schumann, U., \& Heymsfield, A. J. (2017). On the life cycle of individual contrails and contrail cirrus. Meteorological Monographs, 58, 3.1-3.24. https://doi.org/10.1175/AMSMONOGRAP HS-D-16-0005.1.

Sharman, R. D., \& Trier, S. B. (2019). Influences of gravity waves on convectively-induced turbulence (CIT): A review. Pure and Applied Geophysics. https://doi.org/10.1007/s00024-018-1849-2.

Smith, P. (2017). The true story behind the deadliest air disaster of all time. The telegraph. https://www.telegraph.co.uk/travel/ comment/tenerife-airport-disaster/. Accessed 5 Mar 2019.

Storer, L. N., Williams, P. D., \& Gill, P. G. (2019). Aviation turbulence: dynamics, forecasting, and response to climate change. Pure and Applied Geophysics. https://doi.org/10.1007/s00024-018-1822-0.

TC AIM. (2019). Aeronautical information manual. TP 14371E (2019-1). TC. ISSN\#1715-7390.

Thobois, L., Cariou, J. P., \& Gultepe, I. (2019). Review of lidar based applications for aviation weather. Pure and Applied Geophysics. https://doi.org/10.1007/s00024-018-2058-8.

Tomek, D. M., Sewall, W. G., Mason, S. E., \& Szchur, W. A. (2006). Next generation of high-speed dynamic stability wind tunnel testing. In: AIAA 2006-3148, 25th AIAA Aerodynamic Measurement Technology and Ground Testing Conference, San Francisco, CA, June 2006.

Weston, M., Chaouch, N., Valappil, V., Temimi, M., Ek, M., \& Zheng, W. (2019). Assessment of the sensitivity to the thermal roughness length in Noah and Noah-MP land surface model using WRF in an arid region. Pure and Applied Geophysics. https://doi.org/10.1007/s00024-018-1901-2.

Zheng, N., Luo, M., Zou, X., Qiu, X., Lu, J., Han, J., Wang, S., Wei, Y., Zhang, S., \& Yao, H. (2018). A novel method for the recognition of air visibility level based on the optimal binary tree support vector machine. Atmosphere, 9, 481. https://doi.org/10.3390/ atmos 9120481 . 